\title{
Avaliação de linhagens de maxixe paulista cultivadas em canteiros com cobertura de polietileno
}

\author{
Valéria A. Modolo; Cyro Paulino da Costa \\ ESALQ/USP, C. Postal 9, 13418-900 Piracicaba-SP; E-mail: vamodolo@esalq.usp.br
}

\section{RESUMO}

A partir do cruzamento de Cucumis anguria $\mathrm{x}$ Cucumis longipes obtiveram-se, com ciclos de seleção massal intercalados a ciclos de endogamia, linhagens de maxixe que diferem do tipo comum pelas suas características de ausência de espiculosidade, tamanho de fruto e formato de folha não lobulada, semelhante ao pepino. Dez dessas linhagens, eleitas como elites e denominadas maxixe paulista, foram avaliadas quanto ao comportamento e produção de frutos, no sistema de cultivo com cobertura de polietileno e fertirrigação. $\mathrm{O}$ maxixe comum foi utilizado como testemunha. As mudas foram obtidas em bandejas de poliestireno expandido e depois transplantadas para linha central de canteiros cobertos com polietileno preto, adotando-se espaçamento de 1,0 m entre plantas. As plantas foram conduzidas de modo rasteiro, com fertirrigação por gotejamento. $\mathrm{O}$ delineamento experimental foi blocos ao acaso, com quatro repetições e parcela de seis plantas. As linhagens de maxixe paulista apresentaram peso médio de fruto de $66,20 \mathrm{~g}$, sendo, em média, $80 \%$ maior que o tipo comum, que apresentou peso de $36,68 \mathrm{~g}$. O cultivo em canteiros com cobertura de polietileno e fertirrigação por gotejamento proporcionou produtividade estimada de 51,89 $\mathrm{t} \mathrm{ha}^{-1}$ para o maxixe comum, sendo que não houve diferença entre as linhagens e o comum em termos de produtividade.

Palavras-chave: Cucumis anguria L., produção, irrigação por gotejo.

\begin{abstract}
Evaluation of Paulista Gherkin lines grown in beds with polyethylene mulching

New gherkin lines were derived from Cucumis anguria $\mathrm{x}$ Cucumis longipes crossing by mass selection cycles intercalated with inbreeding cycles. The new lines differ from the common type by their absense of prickles, greater fruit size and non-lobular shaped leaves, similar to cucumber ones. Ten of such lines, selected as elite ones and named as Paulista Gherkin, were evaluated for fruit production, under polyethylene covering and fertigation growing system. The common gherkin was used as check. Seedlings were produced in expanded polypropylene trays and transplanted to bed center covered with black polyethylene. Plants were spaced out 1.0 $\mathrm{m}$ apart from each other and conducted in a prostrate habit, under drip fertigation. A randomized block experimental design with four replicates and six plants per plot was used. Paulista Gherkin had $66.2 \mathrm{~g}$ fruits on average, $80 \%$ higher than the common gherkin. The common gherkin had $36.68 \mathrm{~g}$ fruits on average. Gherkins grown in beds with polyethylene mulching plus drip fertigation promoted an estimated yield of $51.89 \mathrm{t} \mathrm{ha}^{-1}$. There was no yield difference beetwen Elite Paulista Gherkins compared with the common one.
\end{abstract}

Keywords: Cucumis anguria L., gherkin, mulching, drip irrigation, yield.

(Recebido para publicação em 27 de junho de 2002 e aceito em 19 de maio de 2003)

$\mathrm{O}$ maxixe (Cucumis anguria L.) é uma cultura de origem africana, bastante cultivada no norte e nordeste do Brasil. As populações brasileiras caracterizam-se pela produção de frutos sem sabor amargo e com variações quanto à espiculosidade e ao tamanho, geralmente com peso médio de $30 \mathrm{~g}$ (Pimentel, 1985). Sua forma de consumo está associada à culinária tradicional do nordeste, onde o fruto maduro é cozido com outros ingredientes, originando o prato típico denominado "maxixada". Apesar de não ser habitual, essa hortaliça também pode ser consumida in natura na forma de salada, substituindo com vantagem o pepino por ser menos indigesta. Sua maior potencialidade seria para o segmento de consumo em conserva na forma de picles (Baird \& Thieret, 1988; Koch \& Costa, 1991; Robinson \& DeckerWalters, 1997).
A partir do cruzamento interespecífico entre Cucumis longipes e cultivares de Cucumis anguria, Koch \& Costa (1991) iniciaram um programa de melhoramento de maxixe conseguindo, entre outras características, quadruplicar o peso do fruto. Após alguns ciclos de seleção massal foram obtidas várias dezenas de linhagens de maxixe que diferem do tipo comum pela ausência de espiculosidade, maior tamanho de fruto e formato de folha não lobulada, semelhante ao pepino. Essas linhagens foram avaliadas (Modolo et al., 1999) e selecionadas, dando origem a um novo tipo que foi denominado maxixe paulista.

O sistema de cultivo do maxixe comum é na sua maioria obsoleto, sendo raramente submetido ao cultivo convencional. É predominantemente coletado a partir de populações sub-espontâneas em roçados ou em plantios de subsistência (Paiva, 1984). Porém, o desenvolvimento e a promoção de um novo produto, como o maxixe paulista, destinado a outros segmentos de mercado, tanto na forma de salada como para conserva, implica modernização de sua tecnologia de produção.

Algumas técnicas de cultivo podem ser empregadas para promover aumento de produtividade e melhoria de qualidade de uma hortaliça. Dentre elas pode-se destacar o cultivo em canteiros com cobertura e uso de fertirrigação, como já vem sendo feito no cultivo do morango há mais de trinta anos. Atualmente, devido às vantagens que esse sistema oferece, a adesão dos produtores a essa tecnologia de produção é total (Goto \& Duarte Filho, 1999). Os efeitos da cobertura de canteiros para as diversas hortaliças são praticamente os 
mesmos: influencia o metabolismo das plantas, acelerando a absorção radicular de água e nutrientes; protege o solo da erosão causada pelo excesso de água de irrigação ou de chuva; aumenta a temperatura do solo nos primeiros $10 \mathrm{~cm}$ de profundidade, favorecendo o desenvolvimento da planta; aumenta o teor de umidade do solo na região radicular; controla algumas espécies de plantas daninhas; aumenta a produção dos cultivos além melhorar a qualidade do produto obtido (Paiva, 1998). Nem sempre esses efeitos são simultâneos e na maioria das vezes é necessário verificar as interações entre a prática olerícola e sua ação no desenvolvimento da planta.

No cultivo convencional do maxixeiro existem variações quanto à produtividade, dependendo da época e do local de cultivo. Na Amazônia, no período de menor pluviosidade, porém, com irrigação e espaçamento de 3,00 x 2,00 m entre plantas, as cultivares maxixe liso e maxixe com espículos produziram 110 e 165 frutos/cova, com peso médio de 37 e $38 \mathrm{~g} /$ fruto, respectivamente (Pimentel, 1985). No Maranhão, a produtividade média é de $16 \mathrm{t} \mathrm{ha}^{-1}$, porém no período chuvoso é reduzida para aproximadamente 8-10 t ha ${ }^{-1}$ (Martins, 1986). Em São Paulo, a produtividade é de 12 t.ha ${ }^{-1}$ sendo cultivado preferencialmente de setembro a fevereiro (Melo \& Trani, 1998). Filgueira (2000) relata que a produtividade da cultura do maxixe se situa em torno de 4-5 t.ha-1.

Não foi encontrada nenhuma referência sobre cultivo de maxixe utilizando cobertura de canteiros com polietileno. No entanto, Leal et al. (2000) verificaram aumento da produtividade da cultura quando utilizou-se palha de palmeira como cobertura de canteiros. Neste sistema, esses autores verificaram produtividade de $17,78 \mathrm{tha}^{-1}$ contrastando com $15,15 \mathrm{t} \mathrm{ha}^{-1}$ no sistema convencional. Para o maxixe paulista, o uso de plástico como cobertura de canteiros associado à fertirrigação poderia constituir um eficiente manejo para aumento da produção, qualidade de frutos e controle de ervas daninhas. Outro fator favorável seria a introdução desse cultivo como alternativa de rotação nas regiões pro- dutoras de morango, onde os produtores aproveitariam a infra-estrutura existente para plantio de maxixe paulista, na época de entressafra.

O objetivo desta pesquisa foi verificar o comportamento e avaliar a produção de dez linhagens de Maxixe Paulista com relação ao manejo de cultivo em campo, utilizando filme de polietileno para cobertura de canteiros e fertirrigação.

\section{MATERIAL E MÉTODOS}

O experimento foi instalado e conduzido de agosto a dezembro de 1999, no campo experimental da ESALQ, em Piracicaba. As coordenadas geográficas do local são $22^{\circ} 42^{\prime} \mathrm{S}, 47^{\circ} 38^{\prime} \mathrm{W}$ e altitude de $575 \mathrm{~m}$. O clima da região é Cwa, subtropical úmido, conforme classificação de Köppen.

As mudas das linhagens designadas como L1, L2, L3, L4, L5, L6, L8, L42, L55 e L60 de maxixe paulista e do maxixe comum foram obtidas em bandejas de poliestireno expandido preenchidas com substrato GII, da empresa Gioplanta. Após 20 dias, as mudas foram transplantadas para bandejas de 72 células, preenchidas com o mesmo substrato. O transplante para o campo ocorreu 47 dias após a semeadura, sendo as mudas dispostas no centro de canteiros com 1,20 m de largura, com espaçamento de 1,0 m entre plantas. Antes do transplante foi realizado o preparo do solo constando de uma aração, duas gradagens e encanteiramento. Os canteiros foram cobertos com filme de polietileno preto de baixa densidade. $\mathrm{O}$ sistema de irrigação utilizado foi do tipo gotejo e a fertirrigação foi feita com o adubo Krystalon, conforme recomendação do fabricante para cultura do pepino. Na fase de estabelecimento da cultura (primeiros 15 dias) foi aplicado 0,3 g L ${ }^{-1}$ de Kirstalon amarelo (13-40-13); na fase de crescimento (16-30 dias), 0,2 $\mathrm{g} \mathrm{L}^{-1}$ de Kristalon branco (15-05-15), 0,1 g L ${ }^{-1}$ de nitrato de cálcio e $0,15 \mathrm{~g} \mathrm{~L}^{-1} \mathrm{de}$ nitrato de magnésio líquido; até o aparecimento do primeiro fruto (31-45 dias), 0,3 $\mathrm{g} \mathrm{L}^{-1}$ de Kristalon branco (1505-15), 0,2 $\mathrm{g} \mathrm{L}^{-1}$ de nitrato de cálcio e $0,15 \mathrm{~g} \mathrm{~L}^{-1}$ de nitrato de magnésio líquido e finalmente, durante a fase de pro- dução, utilizou-se $0,4 \mathrm{~g} \mathrm{~L}^{-1}$ de Kristalon laranja (06-12-06), 0,3 $\mathrm{g} \mathrm{L}^{-1}$ de nitrato de cálcio e $0,9 \mathrm{~g} \mathrm{~L}^{-1}$ de Kristalon vermelho (12-12-36).

As plantas foram conduzidas de modo rasteiro. Quando as ramas laterais apresentavam cerca de $1,0 \mathrm{~m}$ de comprimento foi feita a poda apical da haste principal, para estimular a frutificação nas ramas laterais. O tratamento fitossanitário foi realizado de forma preventiva. Realizaram-se 2 aplicações do inseticida Aplaud (250 $\mathrm{g} \mathrm{kg}^{-1} \mathrm{de}$ buprofezin), na fase de produção de mudas, com intervalo de 10 dias entre

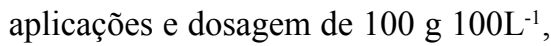
para o controle de mosca branca (Bemisia sp). Após o transplante das mudas fez-se aplicações preventivas com Dithane (800 $\mathrm{g} \mathrm{kg}^{-1}$ de mancozeb), na dosagem de $200 \mathrm{~g} 100 \mathrm{~L}^{-1}$, quando as condições eram propícias ao desenvolvimento de míldio (Pseudoperonospora cubensis). A colheita dos frutos iniciouse 80 dias após a semeadura, sendo realizada durante dois meses, com intervalo de cinco dias, num total de 12 etapas. Colheram-se frutos parcialmente imaturos, quando a sementes ainda não estavam totalmente desenvolvidas, por volta de 20 dias após a antese. A produção foi expressa em número total de frutos/parcela e peso total de frutos/parcela, em quilograma. Posteriormente foi calculado o peso médio de fruto (gramas), e a produtividade por área $\left(\mathrm{t} \mathrm{ha}^{-1}\right)$. Como o experimento foi conduzido em canteiros, para o cálculo de produtividade considerou-se a área ocupada por cada planta de $1,55 \mathrm{~m}^{2}(1,00 \times 1,55 \mathrm{~m})$, resultando-se em uma população aproximada de 6500 plantas $\mathrm{ha}^{-1}$. O delineamento experimental foi blocos ao acaso, com quatro repetições e parcela de seis plantas. Os resultados obtidos para número de frutos foram transformados segundo raiz quadrada de $(\mathrm{x}+0,5)$, para realização da análise de variância e comparação das médias nas etapas de colheita pelo teste de Dunnet. Posteriormente as médias sem transformação foram comparadas pelo Teste Tukey a 5\% de probabilidade.

\section{RESULTADOS E DISCUSSÃO}

Não houve diferença entre as linhagens e o tipo comum para peso de fru- 
Tabela 1. Peso de frutos por planta, em kg, de linhagens de maxixe paulista L1, L2, L3, L4, L5, L6, L8, L42, L55 e L60 e do tipo comum (A), nas seis etapas iniciais de colheita. Piracicaba, ESALQ/USP, 1999.

\begin{tabular}{|c|c|c|c|c|c|c|c|c|c|c|c|c|}
\hline \multirow{2}{*}{$\begin{array}{l}\text { Tipos } \\
\text { Maxixe }\end{array}$} & \multicolumn{12}{|c|}{ Peso de frutos por planta nas etapas de colheita } \\
\hline & $1^{a}$ & $2^{a}$ & $3^{a}$ & $4^{a}$ & $5^{\mathbf{a}}$ & $6^{\mathrm{a}}$ & $7^{a}$ & $8^{a}$ & $9^{a}$ & $10^{\mathrm{a}}$ & $11^{\mathrm{a}}$ & $12^{\mathrm{a}}$ \\
\hline A & 0,09 & 0,18 & 0,38 & 0,62 & 0,78 & 0,31 & 0,60 & 0,30 & 1,36 & 2,02 & 0,77 & 0,57 \\
\hline L1 & 0,02 * & 0,06 * & 0,19 & 0,41 & 0,71 & 0,44 & 0,80 & 0,52 & 0,67 & 0,77 * & 0,70 & 0,77 \\
\hline L2 & 0,12 & 0,26 & 0,39 & 0,86 & 0,61 & 0,51 & 0,81 & 0,56 & 0,44 * & 0,83 * & 0,70 & 0,57 \\
\hline L3 & 0,09 & 0,22 & 0,35 & 0,77 & 0,67 & 0,50 & 1,08 & 0,86 & 0,79 & 1,10 & 1,05 & 0,94 \\
\hline L4 & 0,02 * & 0,06 * & 0,14 * & 0,52 & 0,40 & 0,36 & 0,78 & 0,59 & 0,96 & 0,64 * & 0,62 & 0,52 \\
\hline L5 & 0,01 * & 0,03 * & 0,09 * & 0,28 & 0,43 & 0,45 & 0,79 & 0,53 & 0,72 & 0,76 * & 0,69 & 0,74 \\
\hline L6 & 0,08 & 0,16 & 0,30 & 0,59 & 0,57 & 0,41 & 0,90 & 0,71 & 1,17 & 1,04 * & 0,92 & 0,83 \\
\hline L8 & 0,04 & 0,13 & 0,29 & 0,64 & 0,68 & 0,59 & 1,16 & 0,96 & 0,73 & 0,95 * & 1,12 & 0,96 \\
\hline L42 & 0,02 * & 0,07 & 0,19 & 0,49 & 0,52 & 0,33 & 0,92 & 1,13 * & 1,09 & 0,74 * & 0,63 & 0,50 \\
\hline L55 & 0,03 & 0,08 & 0,17 * & 0,57 & 0,60 & 0,63 & 1,21 & 1,22 * & 1,03 & 0,81 * & 0,89 & 0,79 \\
\hline L60 & 0,03 & 0,14 & 0,21 & 0,51 & 0,56 & 0,46 & 0,89 & 0,69 & 0,72 & $0,46^{*}$ & 0,66 & 0,50 \\
\hline
\end{tabular}

Dentro da coluna, médias seguidas por $(*)$ são significativamente diferente da testemunha (A) pelo teste de Dunnet a $5 \%$ de probabilidade.

Tabela 2. Número de frutos por planta, em kg, de linhagens de maxixe paulista L1, L2, L3, L4, L5, L6, L8, L42, L55 e L60 e do tipo comum (A), nas seis etapas iniciais de colheita. Piracicaba, ESALQ/USP, 1999.

\begin{tabular}{|c|c|c|c|c|c|c|c|c|c|c|c|c|}
\hline \multirow{2}{*}{$\begin{array}{c}\text { Tipos } \\
\text { Maxixe }\end{array}$} & \multicolumn{12}{|c|}{ Números de fruto por planta } \\
\hline & $1^{a}$ & $2^{a}$ & $3^{a}$ & $4^{a}$ & $5^{a}$ & $6^{a}$ & $7^{a}$ & $8^{a}$ & $9^{a}$ & $10^{\mathrm{a}}$ & $11^{\mathrm{a}}$ & $12^{\mathrm{a}}$ \\
\hline A & 3,1 & 6,6 & 11,5 & 18,2 & 22,2 & 9,3 & 15,6 & 8,4 & 41,1 & 56,9 & 20,0 & 13,3 \\
\hline L1 & $0,5^{*}$ & $1,3^{*}$ & $3,3^{*}$ & 7,0 * & 11,3 * & 7,6 & 11,8 & 8,1 & 9,2 * & $11,5^{*}$ & 10,4 & 12,3 \\
\hline L2 & 2,6 & 4,8 & 7,0 & 14,0 & 11,0 * & 9,4 & 13,3 & 9,7 & 7,5 * & 13,8 * & 12,9 & 13,1 \\
\hline L3 & 2,2 & 4,1 & 6,5 & 13,2 & 11,4 * & 8,9 & 16,5 & 13,5 & 12,6 * & 16,0 * & 17,2 & 14,5 \\
\hline L4 & $0,5^{*}$ & 1,3 * & $2,5^{*}$ & 8,2 * & 7,2 * & 6,3 & 12,3 & 10,5 & 12,3 * & 8,9 * & 9,6 * & 7,8 \\
\hline L5 & $0,1^{*}$ & $0,7^{*}$ & 2,0 * & 5,2 * & 7,3 * & 7,9 & 12,8 & 9,0 & 12,1 * & 12,1 * & 12,0 & 12,6 \\
\hline L6 & 2,3 & 3,5 * & 7,0 & 11,5 & $11,4^{*}$ & 7,5 & 15,8 & 12,8 & 20,6 * & $16,5^{*}$ & 15,5 & 14,0 \\
\hline L8 & 0,9 * & 2,5 * & $5,5^{*}$ & 10,9 & 12,6 & 10,7 & 18,3 & 16,4 & $11,7^{*}$ & $13,7^{*}$ & 20,3 & 15,5 \\
\hline L42 & $0,5^{*}$ & 1,6 * & 4,3 * & 13,0 & 10,9 * & 6,8 & 17,8 & 22,3 * & 20,9 * & $15,7^{*}$ & 12,0 & 9,0 \\
\hline L55 & $0,7^{*}$ & $1,7^{*}$ & $3,5^{*}$ & 11,0 & 11,0 * & 11,9 & 20,1 & 21,8 * & 17,3 * & 11,4 * & 15,6 & 13,8 \\
\hline L60 & 0,9 * & $2,8^{*}$ & $4,0^{*}$ & 8,6 * & $9,7^{*}$ & 8,4 & 14,5 & 11,3 & 11,0 * & $6,4^{*}$ & 11,1 & 8,0 \\
\hline
\end{tabular}

Dentro da coluna, médias seguidas por $\left({ }^{*}\right)$ são significativamente diferente da testemunha (A) pelo teste de Dunnet a $5 \%$ de probabilidade.

tos por planta, na maioria das colheitas (Tabela 1). Nas três primeiras colheitas, as linhagens L4 e L5 apresentaram comportamento similar, com produção quatro a nove vezes inferior ao tipo comum. $\mathrm{Na}$ décima colheita houve um pico de produção do tipo comum, sendo somente a linhagem L3 tão produtiva quanto ele.

Com relação ao número de frutos/ planta observou-se que, de maneira geral, nas quatro primeiras colheitas o comum produziu significativamente maior número de frutos que as linhagens, exceto L2, L3 e L6 (Tabela 2). Na sexta e sétima colheita, esse comportamento não se manteve, pois as linhagens do paulista foram equivalentes ao comum. $\mathrm{Na}$ quinta, nona e principalmente na décima colheita, o maxixe comum mostrou ser altamente prolífico, sendo que nessa última sua produção em número de frutos foi 3,5 vezes maior que a linhagem mais prolífica L6 e 9 vezes maior que a menos prolífica, L60. Segundo Yokoyama \& Silva Júnior (1988), o ponto máximo de crescimento do fruto do maxixe comum ocorre em torno do décimo primeiro e décimo segundo dia após a antese. Neste ponto o fruto estaria parcialmente maduro e pronto para o consumo na forma tradicional, onde ele é cozido. Para o maxixe paulista este estágio de maturação ocorre aos vinte e cinco dias após a antese, dado que este apresenta uma formação lenta de sementes (Modolo \& Costa, 2000). Neste experimento, como os frutos tanto das linhagens como do tipo comum foram colhidos na mesma época, houve diferentes picos de produção devido às diferenças de desenvolvimento de fruto entre o comum e as linhagens.

Considerando-se o número de frutos produzidos em todas as etapas de colheita, verificou-se que as linhagens 
Tabela 3. Número total (NTF), peso total (PTF) e peso médio (PM) de frutos por planta de maxixe paulista L1; L2; L3; L4; L5; L6; L8; L42; L55 e L60 e do tipo comum (A), após 12 colheitas. Piracicaba, ESALQ/USP, 1999.

\begin{tabular}{lrcc}
\hline \multicolumn{1}{c}{ Tipos de maxixe } & NTF & PTF $(\mathbf{k g})$ & PM $(\mathbf{g})$ \\
\hline A & $217,67 \mathrm{a}$ & $7,98 \mathrm{a}$ & $36,68 \mathrm{~b}$ \\
L1 & $86,17 \mathrm{~b}$ & $6,07 \mathrm{a}$ & $70,48 \mathrm{a}$ \\
L2 & $109,33 \mathrm{~b}$ & $6,66 \mathrm{a}$ & $60,95 \mathrm{a}$ \\
L3 & $123,00 \mathrm{ab}$ & $8,42 \mathrm{a}$ & $68,47 \mathrm{a}$ \\
L4 & $77,00 \mathrm{~b}$ & $5,61 \mathrm{a}$ & $72,90 \mathrm{a}$ \\
L5 & $84,67 \mathrm{~b}$ & $5,52 \mathrm{a}$ & $65,22 \mathrm{a}$ \\
L6 & $125,33 \mathrm{ab}$ & $7,68 \mathrm{a}$ & $61,33 \mathrm{a}$ \\
L8 & $122,50 \mathrm{ab}$ & $8,24 \mathrm{a}$ & $67,28 \mathrm{a}$ \\
L42 & $112,33 \mathrm{~b}$ & $6,61 \mathrm{a}$ & $58,86 \mathrm{a}$ \\
L55 & $118,00 \mathrm{ab}$ & $8,05 \mathrm{a}$ & $68,23 \mathrm{a}$ \\
L60 & $85,33 \mathrm{~b}$ & $5,82 \mathrm{a}$ & $68,24 \mathrm{a}$ \\
\hline C.V. & $25,45 \%$ & $27,46 \%$ & $8,04 \%$ \\
\hline
\end{tabular}

Dentro da coluna, médias seguidas pela mesma letra não diferem entre si pelo Teste de Tukey a 5\% de probabilidade.

foram equivalentes entre si e menos prolíficas que o comum. Apenas as linhagens L3, L6, L8 e L55 foram semelhantes em termos de prolificidade ao tipo comum (Tabela 3). Essa equivalência quanto a menor prolificidade das linhagens elite de maxixe pode ser explicada pelo processo seletivo que as originou. Similarmente como ocorre em pepino, se no processo de seleção para obtenção de linhagens for priorizado maior peso médio de fruto, consequentemente o número total de frutos produzidos tenderá a diminuir, porém sem redução na produção total (Simmonds, 1979). Da mesma forma, plantas de pepino com maior número de frutos tendem a produzir frutos com menor peso médio e comprimento (Ramalho, 1973). O mesmo pode ter ocorrido com as linhagens de maxixe paulista, pois o critério mais importante no processo foi o peso médio de fruto maduro, podendo ter proporcionado diminuição na produção total em número total de frutos, porém sem interferir na produção total por área.

Considerando-se uma população de 6.500 plantas ha $^{-1}$, estima-se neste experimento uma produtividade para o maxixe comum de 51,89 tha ${ }^{-1}$. A média de produtividade para o estado de São Paulo em condições convencionais para uma população de 13.000 plantas ha-1 tem sido de $12 \mathrm{t} \mathrm{ha}^{-1}$ (Melo \& Trani, 1998). Para as diferentes regiões produtoras de maxixe, a produtividade va- ria de 4 a 16 t ha $^{-1}$ (Pimentel, 1985; Martins, 1986; Filgueira, 2000). Isso mostra ganhos em produtividade total no sistema de manejo com cobertura plástica de canteiros e fertirrigação por gotejamento, no qual foi obtida produtividade três a treze vezes maior que a descrita na literatura para cultivo convencional.

O parâmetro que melhor caracteriza as diferenças entre o maxixe comum e o paulista é o peso médio do fruto. $\mathrm{O}$ maxixe comum apresenta peso médio variando de 14,57 a 45,70 g dependendo da cultivar, da época de plantio e da região produtora (Pimentel, 1985; Resende, 1998). Isso concorda com o encontrado neste experimento onde a média de peso/fruto foi de $36,68 \mathrm{~g}$. As linhagens de maxixe paulista apresentaram peso médio de fruto de $66,20 \mathrm{~g}$, sendo, em média, $80 \%$ maior que o tipo comum (Tabela 3). Entre as linhagens não houve diferença neste aspecto podendo qualquer uma delas ser utilizada como nova variedade.

Torna-se importante ressaltar que o sistema de comercialização de hortaliças no atacado é baseado em volume de frutos, enquanto no varejo é feito com base no peso do produto. No Brasil, a embalagem mais utilizada na comercialização do maxixe comum é a caixa tipo "K", com $20 \mathrm{~kg}$ do produto (Filgueira, 2000). Considerando-se um peso médio de fruto maior, seria neces- sário menor número de frutos para completar o mesmo volume de comercialização, o que traria economia de mão de obra, tanto na colheita, quanto na embalagem do produto. Outra vantagem do aumento do peso médio do fruto seria a inserção desse novo produto no consumo in natura, na forma de salada. Tradicionalmente, para o preparo do maxixe comum, os frutos são raspados para retirada dos espinhos e da casca e, devido ao seu tamanho, estes são colocados inteiros para o cozimento com outros ingredientes. No maxixe paulista, além do uso na forma cozida, os frutos com casca lisa e dimensões maiores facilitariam o corte em fatias, como é feito com o pepino, para o consumo em saladas.

Algumas considerações podem ser feitas quanto ao comportamento do cultivo do maxixe no manejo adotado. $\mathrm{O}$ espaçamento de 1,0 m entre plantas mostrou ser competitivo, com ampla cobertura do solo, o que dificultou o manuseio das plantas na fase final das etapas de colheita. O hábito de crescimento prostrado e a intensa ramificação secundária e terciária fizeram com que as ramas crescessem para fora da cobertura de polietileno. Como conseqüência houve pisoteio com danos às ramificações ao longo dos espaços entre os canteiros, nas etapas finais de colheita. Com isso, as vantagens diretas na qualidade dos frutos oferecidas pelo uso da cober- 
tura de solo foram restritas somente às primeiras etapas de colheita. Se considerarmos o cultivo de maxixe como alternativa para produtores de morango, como cultura de entressafra, maiores estudos deveriam ser realizados para que a produção dos frutos pudesse ser concentrada sobre a cobertura.

\section{LITERATURA CITADA}

BAIRD, J.R.; THIERET, J.W. The bur gherkin (Cucumis anguria var. anguria, Cucurbitaceae) Economy Botany, v. 42, n. 3, p. 447-451, 1988. GOTO, R.; DUARTE FILHO, J. Utilização de plástico na cultura do morangueiro. Informe Agropecuário, Belo Horizonte, v. 20, n. 198, p. 59-64, 1999.

FILGUEIRA, F.A.R. Novo manual de Olericultura: agrotecnologia moderna na produção e comercialização de hortaliças. Viçosa: UFV, 2000. 402 p.

KOCK, P.S.; COSTA, C.P. Herança de caracteres de planta e fruto em maxixe. Horticultura Brasileira, Brasília, v. 9, n. 2, p. 73-77, 1991.
LEAL, F.R.; SANTOS, V.B.; SALVIANO, A.A.C. Sistemas de condução e aplicação de cal extinta na cultura do maxixe. Horticultura Brasileira, Brasília, v. 18, Suplemento, p. 542-543, 2000.

MARTINS, M.A.S. Maxixe (Cucumis anguria L.) e seu cultivo em São Luís do Maranhão. São Luís: EMAPA, 1986 (Documento, 8).

MELO, A.M.T.; TRANI, P.S. Maxixe. In: FAHL, J.I.; CAMARGO, M.B.P.; PIZZINATTO, M.A.; BETTI, J.A.; MELO, A.M.T.; MARIA, I.C.; FURLANI, A.M.C. (Eds). Instruções agrícolas para as principais culturas econômicas. Campinas: Instituto Agronômico, 1998. 393 p. (IAC. Boletim Técnico 200).

MODOLO, V.A.; COSTA, C.P.; TESSARIOLI NETO, J. Caracterização de linhagens melhoradas de maxixe. In: CONGRESSO BRASILEIRO DE OLERICULTURA, 39., 1999, Tubarão, Anais... Tubarão: SBO, 1999, p. 201

MODOLO, V.A.; COSTA, C.P. Caracterização de frutificação e ponto de colheita em maxixe. Horticultura Brasileira, Brasília, v. 18, Suplemento, p. 476-478, 2000.

PAIVA, M.C. Produção de hortaliças em ambiente protegido. Cuiabá: SEBRAE/MT, 1998. 78 p. (Coleção Agroindústria, 18).
PAIVA, W.O. Estimativas de parâmetros genéticos em maxixe (Cucumis anguria L.). Acta Amazonica, Manaus, v. 14, n. 1/2, p. 39-47, 1984. PIMENTEL, A.A.M.P. Olericultura no trópico úmido: hortaliças da Amazônia. São Paulo: Agronômica Ceres, 1985. 332 p.

RAMALHO, M.A.P. Hábito de florescimento $e$ frutificação do pepino (Cucumis sativus L.). Piracicaba: ESALQ/USP, 1973. 48 p. (Dissertação mestrado)

RESENDE, G.M. Rendimento de cultivares de maxixe em função de épocas de cultivo. Horticultura Brasileira, Brasília, v. 16, n. 2, p. 167-171, 1998.

ROBINSON, R.W.; DECKER-WALTERS, D.S. Cucurbits. New York: CAB International, 1997. $225 \mathrm{p}$.

SIMMONDS, N.W. Principles of crop improvement. New York: Longman Group Limited, 1979. 408 p.

YOKOYAMA, S.; SILVA JÚNIOR, A.A. Maxixe: uma hortaliça pouco conhecida. Agropecuária Catarinense, Santa Catarina, v. 1, n. 3, p. 12-13, 1988. 